\title{
Herança da resistência do Híbrido de Timor UFV 443-03 à ferrugem-do-cafeeiro
}

\author{
Alexandre Sandri Capucho(1), Eveline Teixeira Caixeta(2), Eunize Maciel Zambolim(1) e Laércio Zambolim(1)
}

(1)Universidade Federal de Viçosa, Instituto de Biotecnologia Aplicada à Agropecuária, Av. P.H. Rolfs, s/no , Campus Universitário, CEP $36570-000$ Viçosa, MG. E-mail: alexandre.capucho@ufv.br, eunize@ufv.br, zambolim@ufv.br (2)Embrapa Café, Parque Estação Biológica, Av. W3 Norte (final), CEP 70770-901 Brasília, DF. E-mail: eveline.caixeta@embrapa.br

\begin{abstract}
Resumo - O objetivo deste trabalho foi caracterizar a herança da resistência do Híbrido de Timor UFV 443-03 à ferrugem-do-cafeeiro (Hemileia vastatrix). Para isso, a raça II e o patótipo 001 de ferrugem foram inoculados em 246 plantas da população $\mathrm{F}_{2}, 115$ plantas do retrocruzamento suscetível $\left(\mathrm{RC}_{\mathrm{S}}\right)$ e 87 plantas do retrocruzamento resistente $\left(\mathrm{RC}_{\mathrm{R}}\right)$, originadas do cruzamento entre o genótipo suscetível cv. Catuaí Amarelo IAC 64 e a fonte de resistência Híbrido de Timor UFV 443-03. Para ambos os inóculos, a cv. Catuaí Amarelo IAC 64 foi suscetível, enquanto o Híbrido de Timor UFV 443-03, a planta representante da geração $\mathrm{F}_{1}$ e as plantas do $\mathrm{RC}_{\mathrm{R}}$ foram resistentes. As plantas $\mathrm{F}_{2}$, quando inoculadas com a raça II, apresentaram dois padrões de segregação significativos: 15:1 e 61:3. A herança da resistência foi confirmada pela inoculação das plantas do $\mathrm{RC}_{\mathrm{S}}$, que segregaram na proporção de 3:1, padrão esperado para herança condicionada por dois genes. A hipótese de segregação 7:1 para três genes foi rejeitada. Resultados semelhantes foram obtidos para o patótipo 001. Dois genes dominantes e independentes conferem a resistência genética do Híbrido de Timor UFV 443-03 à raça II e ao patótipo 001 de $H$. vastatrix.
\end{abstract}

Termos para indexação: Coffea arabica, Hemileia vastatrix, herança genética, resistência a doenças, resistência vertical.

\section{Inheritance of coffee leaf rust resistance in Timor Hybrid UFV 443-03}

\begin{abstract}
The aim of this work was to characterize the resistance inheritance of the Timor Hybrid UFV 443-03 to coffee leaf rust (Hemileia vastatrix). For this, the race II and pathotype 001 of coffee leaf rust were inoculated in $246 \mathrm{~F}_{2}$ plants, 115 susceptible backcrossing $\left(\mathrm{BC}_{\mathrm{S}}\right)$ plants, and 87 resistant backcrossing $\left(\mathrm{BC}_{\mathrm{R}}\right)$ plants, derived from the crossing between the susceptible genotype 'Catuaí Amarelo' IAC 64 and the resistance source Timor Hybrid UFV 443-03. For both inoculums, the 'Catuaí Amarelo' IAC 64 was susceptible, while the Timor Hybrid, the plant representing $\mathrm{F}_{1}$ generation, and the $\mathrm{BC}_{\mathrm{R}}$ plants were resistant. The $\mathrm{F}_{2}$ plants inoculated with race II presented two significant segregation ratios: 15:1 and 61:3. The resistance inheritance was verified by the inoculation of the $\mathrm{BC}_{\mathrm{S}}$ plants, which segregated at a 3:1 ratio, an expected pattern for the inheritance controlled by two genes, whereas the segregation hypothesis of 7:1 for three genes was rejected. Two independent and dominant genes confer the genetic resistance of Timor Hybrid UFV 443-03 to race II and pathotype 001 of H. vastatrix.
\end{abstract}

Index terms: Coffea arabica, Hemileia vastatrix, genetic inheritance, diseases resistance, vertical resistance.

\section{Introdução}

A ferrugem-do-cafeeiro, causada pelo fungo Hemileia vastatrix Berk. et Br., é considerada a principal doença dessa cultura, e seu controle pode ser eficientemente realizado por medidas de natureza química e genética (Zambolim et al., 1999). Apesar da eficiência dos fungicidas, o desenvolvimento de cultivares com resistência genética é economicamente a melhor alternativa para o controle da doença (Waller et al., 2007). No entanto, a obtenção de cultivares resistentes tem sido um constante desafio para os melhoristas, uma vez que, ao longo do tempo, as plantas podem tornar-se suscetíveis a novas raças do patógeno (Várzea \& Marques, 2005).

No Brasil,noperíodode 1999 a 2007, foram colocadas 104 cultivares melhoradas de cafeeiro à disposição dos produtores (Ministério da Agricultura, Pecuária e Abastecimento, 2008). Desse total, 49 possuem resistência vertical ou horizontal a $H$. vastatrix, sendo 17 originadas de cruzamentos com acessos do Híbrido de Timor. Na Colômbia, o sistema multilinha foi usado 
para desenvolver a cultivar Colombia, formada por plantas derivadas de acessos do Híbrido de Timor com diferentes genes de resistência (Castillo, 1989; Alvarado, 2005).

O Híbrido de Timor e as progênies derivadas do seu cruzamento com outras cultivares vêm sendo estudados, em diversas regiões cafeeiras do mundo, como fonte de resistência a $H$. vastatrix (Várzea \& Marques, 2005). O Híbrido de Timor é, provavelmente, um híbrido natural entre Coffea arabica e C. canephora (Bettencourt, 1973; Rodrigues Júnior et al., 2004). Esse germoplasma tem sido valioso para os programas de melhoramento com vistas à obtenção de resistência durável à ferrugem, além de apresentar resistência a outras doenças e pragas do cafeeiro.

Portanto, o conhecimento da herança da resistência do Híbrido de Timor a $H$. vastatrix é importante para o entendimento da base genética da resistência a essa doença. Em geral, a herança da resistência no patossistema Coffea spp. vs. H. vastatrix foi pouco estudada. Os trabalhos existentes, além de escassos, são pouco informativos (Pereira, 1995; Prakash et al., 2004; Brito, 2007).

Até o momento, foram identificados nove genes dominantes de resistência em plantas de café de diferentes espécies, caracterizados pela sigla $\mathrm{S}_{\mathrm{H}}$ (Noronha-Wagner \& Bettencourt, 1967; Bettencourt \& Noronha-Wagner, 1971; Bettencourt \& Rodrigues Júnior, 1988). Esses genes de resistência foram encontrados, principalmente, em C. arabica $\left(\mathrm{S}_{\mathrm{H}} 1,2\right.$, $4,5)$, C. canephora $\left(\mathrm{S}_{\mathrm{H}} 6,7,8,9\right)$ e C. liberica $\left(\mathrm{S}_{\mathrm{H}} 3\right)$. Os genes $\mathrm{S}_{\mathrm{H}} 6,7,8$ e 9 também foram encontrados em derivados do Híbrido de Timor. Além desses, foram detectados pelo menos mais dois genes de resistência ainda não caracterizados, que, isoladamente ou associados aos genes $\mathrm{S}_{\mathrm{H}} 1-\mathrm{S}_{\mathrm{H}} 9$, condicionam resistência a mais de 40 raças fisiológicas de ferrugem (Várzea et al., 2005).

O conhecimento da maneira pela qual os genes $\mathrm{S}_{\mathrm{H}}$ são herdados é de extrema importância para os programas de melhoramento que buscam resistência duradoura a $H$. vastatrix, um fungo que apresenta elevada variabilidade genética. Os genes $S_{H} 1,2,4$ e 5, encontrados em C. arabica, já foram suplantados por diversas raças de $H$. vastatrix (Bettencourt \& Noronha-Wagner, 1971), inclusive as identificadas no Brasil (Cardoso, 1986). Portanto, os programas de melhoramento do cafeeiro buscam a resistência em outras espécies e híbridos interespecíficos, como o Híbrido de Timor.

O objetivo deste trabalho foi determinar o número de genes envolvidos e caracterizar a herança da resistência do Híbrido de Timor UFV 443-03 à raça II e ao patótipo 001 de H. vastatrix.

\section{Material e Métodos}

O Híbrido de Timor UFV 443-03 foi autofecundado e as plantas originadas foram usadas para confirmar a homozigose dos genes de resistência. Para o estudo da herança da resistência do Híbrido de Timor UFV 443-03 a $H$. vastatrix, esse genótipo foi usado como genitor masculino no cruzamento controlado com a cultivar suscetível Catuaí Amarelo IAC $64\left(\mathrm{~S}_{\mathrm{H}} 5\right)$. Uma planta da geração $\mathrm{F}_{1}$, denominada $\mathrm{H}$ 511-1, foi submetida à autofecundação controlada, para obtenção da geração segregante $F_{2}$ (246 plantas). A planta $F_{1} H$ 511-1 foi retrocruzada com o Híbrido de Timor UFV 443-03 $\left(\mathrm{RC}_{\mathrm{R}}, 87\right.$ plantas) e com o Catuaí Amarelo IAC 64 (RCs, 115 plantas).

Os cruzamentos para a obtenção da geração $\mathrm{F}_{1}$ foram realizados por Pereira (1995). O Híbrido de Timor UFV 443-03, o genótipo Catuaí Amarelo IAC 64 e o híbrido $F_{1}$ encontram-se no Campo de Seleção de Híbridos da Universidade Federal de Viçosa (UFV), Viçosa, MG. Um total de 501 plantas foi utilizado, correspondente às mudas da autofecundação controlada do Híbrido de Timor UFV 443-03, dos retrocruzamentos e da geração $F_{2}$. Essas plantas foram produzidas em 2004/2005 e transplantadas para o campo em 2006.

A raça II de $H$. vastatrix utilizada neste trabalho foi caracterizada biologicamente por Cardoso (1986) e, desde então, tem sido mantida pelo Laboratório de Biotecnologia do Cafeeiro (BioCafé/UFV) por inoculações periódicas em mudas da cv. Catuaí Vermelho UFV 2144. Um isolado, designado patótipo 001, também foi usado neste estudo de herança genética. $\mathrm{O}$ patótipo 001 foi coletado de uma lesão monopustular, em lavoura comercial da cv. Oeiras, na região de Viçosa, MG. Esse isolado foi selecionado por ser capaz de infectar essa cultivar, que é derivada do cruzamento entre o Híbrido de Timor CIFC 832/1 e a cv. Caturra Vermelho CIFC 19/1, além de infectar a cultivar Icatú Vermelho, derivada do cruzamento artificial entre C. canephora e C. arabica. Esses genótipos foram lançados comercialmente no 
Brasil como resistentes à raça II de $H$. vastatrix há cerca de 9 e 15 anos, respectivamente. Apesar de a resistência vertical ter sido suplantada nesses cafeeiros, possivelmente por uma nova raça do patógeno, a resistência horizontal tem sido observada em campo.

Para a obtenção dos isolados monopustulares, uma única pústula da raça II e do patótipo 001 foram transferidas, separadamente, multiplicadas na cv. Catuaí Vermelho UFV 2144 e mantidas em compartimentos individualizados, para evitar contaminações. A metodologia usada para a obtenção de isolados monopustulares foi semelhante à descrita para Puccinia conorata (Leonard et al., 2005), Puccinia recondita (Elyasi-Gomari \& Panteleev, 2006) e Puccinia tritici (Kolmer et al., 2007, 2008). No patossistema Coffea spp. vs. H. vastatrix, este é o primeiro estudo de herança em que o inóculo utilizado nos ensaios foi derivado de lesões monopustulares de $H$. vastatrix. Para confirmar a caracterização biológica do patógeno, os uredosporos monopustulares foram inoculados nos clones diferenciadores de raças de H. vastatrix do CIFC (Centro de Investigação das Ferrugens do Cafeeiro), mantidos pelo BioCafé/UFV.

A multiplicação dos uredosporos foi realizada pela metodologia de Zambolim \& Chaves (1974). Este método consiste na deposição de uredosporos, com auxílio de um pincel, na face abaxial de folhas jovens e completamente desenvolvidas do cafeeiro cv. Catuaí Vermelho UFV 2144. Em seguida, as folhas são aspergidas com água destilada até a obtenção de um leve molhamento superficial. As plantas foram mantidas no escuro, a $22^{\circ} \mathrm{C}$ e umidade relativa próxima a $100 \%$, por 48 horas e, em seguida, transferidas para uma câmara de crescimento, com temperatura de $22^{\circ} \mathrm{C}$ e fotoperíodo de 12 horas. Após abundante esporulação, os uredosporos foram coletados e acondicionados em ampolas de vidro vedadas com algodão. As ampolas foram colocadas dentro de um dessecador com solução de ácido sulfúrico (densidade de 1,8 e concentração $32,6 \%$ ) na parte inferior, de modo a manter a umidade relativa em torno de $50 \%$, no ambiente interno. $\mathrm{O}$ dessecador foi acondicionado em refrigerador a $4^{\circ} \mathrm{C}$.

A viabilidade dos uredosporos de $H$. vastatrix foi avaliada pelo teste de germinação em meio ágarágua $2 \%$, usando o método descrito por Zambolim \& Chaves (1974), antes da inoculação nas plantas das populações de cafeeiros. Somente os uredosporos com viabilidade superior a $30 \%$ foram considerados adequados para os testes de inoculação.

A caracterização biológica de raças foi determinada de acordo com a reação de resistência (ausência de uredosporos do patógeno) ou suscetibilidade (presença de uredosporos do patógeno), apresentada pelos clones diferenciadores de raças do CIFC. Para esse fim, utilizou-se a metodologia de disco de folhas, com duas repetições cada (Tamayo et al., 1995).

A caracterização da herança da resistência das populações também foi realizada em discos de folhas, porém com três repetições (Tamayo et al., 1995). A eficiência dessa metodologia para estudos de resistência vertical e horizontal foi demonstrada por Eskes (1982). Para cada planta das diferentes populações e em cada repetição, foram usados 16 discos de folhas, de $1,5 \mathrm{~cm}$ de diâmetro, que constituíram as unidades amostrais. Foram consideradas suscetíveis as plantas que apresentaram uredosporos do patógeno em pelo menos duas repetições. Para evitar erros nas avaliações, foram realizadas inoculações em diferentes datas. Essa medida se deve ao fato de $H$. vastatrix ser um fungo biotrófico, ou seja, necessitar de hospedeiro vivo e bem nutrido para seu pleno desenvolvimento. Além desse cuidado, inoculações adicionais foram realizadas em plantas nas quais houve dúvidas quanto à avaliação fenotípica.

Uredosporos do patógeno foram inoculados em cada disco, na face abaxial, com o auxílio de pincel. Após a inoculação, os discos foram colocados sobre uma tela de náilon e espuma saturada com água no interior de um gerbox (caixa plástica de $11 \times 11 \times 3 \mathrm{~cm}$ ) e, então, atomizados com água destilada. Os gerbox contendo os discos de folhas foram fechados e mantidos na ausência de luz durante 48 horas a $22^{\circ} \mathrm{C}$ e, em seguida, transferidos para uma câmara sob condições controladas de temperatura e luminosidade $\left(22^{\circ} \mathrm{C}, 12\right.$ horas de luz $)$ (Tamayo et al., 1995). Os discos foram limpos com o auxílio de algodão 48 horas após a inoculação. Para eliminar falsos positivos, foram deixados quatro discos de cada amostra sem inoculação.

Durante a incubação, o nível de água no interior dos gerbox foi verificado semanalmente e, após o período latente do controle positivo (progenitor suscetível) - entre 25 e 30 dias -, foi iniciada a avaliação da resistência vertical das populações. As plantas das populações inoculadas foram classificadas como resistentes ou suscetíveis, com base na ausência ou presença de uredosporos do patógeno, respectivamente. 
A análise da segregação fenotípica das plantas foi realizada por meio do teste qui-quadrado $\left(\chi^{2}\right)$, com uso do programa GENES (Cruz, 2006). As diferentes proporções fenotípicas napopulação $\mathrm{F}_{2}$ foram analisadas para herança condicionada por um gene (3:1), dois genes $(15: 1,13: 3$ e 9:7) e três genes $(63: 1,61: 3,55: 9$, $37: 27,57: 7,51: 13,49: 15$ e 43:21), e confirmadas para um gene $(1: 1)$, dois genes $(3: 1)$ e três genes $(7: 1)$ na população de retrocruzamento suscetível. Procurouse detectar, entre as proporções esperadas, aquelas que melhor explicavam as frequências de classes fenotípicas observadas. Assim, aceitar a hipótese de nulidade implicou a obtenção de segregações esperadas iguais às observadas, a $5 \%$ de probabilidade.

\section{Resultados e Discussão}

Tanto o patótipo 001 quanto a raça II apresentaram reação de suscetibilidade, no diferenciador do grupo fisiológico 'E', e de resistência, nos diferenciadores dos outros grupos fisiológicos que receberam inoculação (A, $\alpha, \mathrm{O}, \mathrm{T}, \mathrm{R}, \mathrm{I}, \mathrm{C}, \mathrm{Y}, \mathrm{D}, \mathrm{G}, \mathrm{J}, \mathrm{L}, \mathrm{Z}, \mathrm{W}, \mathrm{M}, 3,1$ ). Estes resultados caracterizam ambos os inóculos como raça II (v5). Entretanto, o patótipo 001 infectou também as cultivares Oeiras e Icatú Vermelho, enquanto a raça II, caracterizada por Cardoso (1986), não as infectou. Esses resultados indicam que o patótipo 001 apresenta um ou mais genes de virulência não detectado(s) pelos diferenciadores de raças utilizados. Como as cultivares Oeiras e Icatú Vermelho, lançadas como resistentes à raça II, apresentam gene(s) de resistência diferente(s) das plantas do grupo fisiológico 'E', é possível que o patótipo 001 seja uma nova raça de $H$. vastatrix.

Nos últimos anos, amostras de $H$. vastatrix coletadas em derivados de Híbrido de Timor, como
Catimor, Sarchimor e na cultivar Colombia, têm sido caracterizadas incorretamente como raça II (v5) (Várzea \& Marques, 2005). Esses autores caracterizaram 12 isolados do fungo, coletados na cultivar Colombia, como raça II e, após inoculações adicionais, verificaram que esses isolados apresentavam outros genes de virulência (v5,? ou v5,7,? ou v5,7,9,?).

Portanto, o patótipo 001 (P001), embora caracterizado como raça II pela série diferenciadora de raças, pode apresentar gene(s) de virulência adicional(is) (v5,?), uma vez que infecta genótipos com outros genes de resistência. Este resultado demonstra a incapacidade da série diferenciadora disponível de distinguir raças de $H$. vastatrix com amplo espectro de virulência.

Todas as plantas provenientes da autofecundação do Híbrido de Timor UFV 443-03 apresentaram resistência vertical (Tabelas 1 e 2). Esses resultados indicam que os locos dos genes de resistência existentes no acesso UFV 443-03 estão em homozigose. Portanto, nos testes de segregação do estudo de herança realizados, considerou-se a hipótese de homozigose dos locos do progenitor resistente.

No estudo de herança para a raça II de $H$. vastatrix, o progenitor feminino cv. Catuaí Amarelo IAC 64 mostrou-se suscetível, enquanto a planta $F_{1}$ H 511-1 avaliada foi resistente (Tabela 1). As 87 plantas do retrocruzamento resistente $\left(\mathrm{RC}_{\mathrm{R}}\right)$ também se mostraram resistentes $\left(\chi^{2}=0,000\right.$; probabilidade $(\mathrm{P})=1$; Tabela 1$)$. Esses resultados indicam que os genes de resistência à ferrugem, presentes no Híbrido de Timor UFV 443-03, são dominantes.

$\mathrm{Na}$ geração $\mathrm{F}_{2}$, em um total de 246 plantas, foi observada resistência em 235 (95,5\%) e suscetibilidade em 11 plantas $(4,5 \%)$. Os resultados obtidos pelo

Tabela 1. Segregação de resistência (R) e suscetibilidade (S) à raça II de Hemileia vastatrix, nas populações analisadas de cafeeiros.

\begin{tabular}{|c|c|c|c|c|c|c|c|c|}
\hline \multirow[t]{2}{*}{ Populações $^{(1)}$} & \multicolumn{2}{|c|}{ Número de plantas } & \multicolumn{2}{|c|}{ Proporção observada } & \multicolumn{2}{|c|}{ Proporção esperada } & \multirow[t]{2}{*}{$\chi^{2}$} & \multirow[t]{2}{*}{ Probabilidade } \\
\hline & $\mathrm{R}$ & $\mathrm{S}$ & $\mathrm{R}$ & $\mathrm{S}$ & $\mathrm{R}$ & $\mathrm{S}$ & & \\
\hline 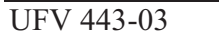 & 1 & 0 & 1,0 & 0 & 1 & 0 & - & - \\
\hline UFV 443-03 ® & 50 & 0 & 1,0 & 0 & 1 & 0 & 0,000 & 1,000 \\
\hline IAC 64 & 0 & 1 & 0,0 & 1 & 0 & 1 & - & - \\
\hline $\mathrm{F}_{1} \mathrm{H} 511-1$ & 1 & 0 & 1,0 & 0 & 1 & 0 & - & - \\
\hline $\mathrm{RC}_{\mathrm{R}}$ & 87 & 0 & 1,0 & 0 & 1 & 0 & 0,000 & 1,000 \\
\hline $\mathrm{F}_{2}(\mathrm{H}$ 511-1) & 235 & 11 & 21,4 & 1 & $15^{(2)}$ & 1 & 1,327 & 0,249 \\
\hline $\mathrm{RC}_{\mathrm{S}}$ & 80 & 35 & 2,3 & 1 & $3^{(2)}$ & 1 & 1,811 & 0,178 \\
\hline $\mathrm{F}_{2}(\mathrm{H}$ 511-1) & 235 & 11 & 64,0 & 3 & $61^{(3)}$ & 3 & 0,025 & 0,872 \\
\hline $\mathrm{RC}_{\mathrm{S}}$ & 80 & 35 & 2,3 & 1 & $7^{(3)}$ & 1 & 33,819 & 0,000 \\
\hline
\end{tabular}

${ }^{(1)} \otimes$, autofecundação controlada; $\mathrm{RC}_{\mathrm{R}}$, retrocruzamento resistente; $\mathrm{RC}_{\mathrm{S}}$, retrocruzamento suscetível. ${ }^{(2)}$ Hipótese de segregação para dois genes:, 15:1 na geração $F_{2}$ e 3:1 no $\mathrm{RC}_{\mathrm{s}}{ }^{(3)}$ Hipótese de segregação de três genes: 61:3 na geração $\mathrm{F}_{2}$ e 7:1 no $\mathrm{RC}_{\mathrm{s}}$. 
teste qui-quadrado (Tabela 1) possibilitam duas interpretações. Na primeira, a resistência é governada por três genes independentes, dois dominantes e um recessivo, demonstrada pela segregação de 61:3 $\left(\chi^{2}=0,025 ; \mathrm{P}=0,872\right)$. Na segunda, a resistência é governada por dois genes dominantes e independentes, o que é indicado pelo padrão de segregação de 15:1 $\left(\chi^{2}=1,327 ; P=0,249\right)$. Inicialmente, considerou-se que a segregação de $61: 3$ seria a mais adequada, uma vez que esta proporção ajustou-se melhor à proporção esperada, pelo teste qui-quadrado. Para confirmar esses resultados, 115 plantas da população de retrocruzamento suscetível $\left(\mathrm{RC}_{\mathrm{S}}\right)$ receberam inoculação, e observouse resistência vertical em 80 plantas $(69,6 \%)$ e suscetibilidade em 35 (30,4\%). Assim, foram testadas as proporções fenotípicas de 7:1, esperada para três genes, e 3:1, esperada para dois genes. A hipótese de segregação $3: 1\left(\chi^{2}=1,811 ; \mathrm{P}=0,178\right)$ não foi rejeitada, enquanto a outra (7:1), sim. Esses resultados indicam que a segregação adequada na população $\mathrm{F}_{2}$ seria de 15:1 e não 61:3, como sugerido apenas pela análise da população $F_{2}$, o que demonstra a importância da inoculação de diferentes populações para uma melhor segurança na interpretação dos dados.

$\mathrm{Na}$ caracterização da resistência do Híbrido de Timor UFV 443-03 ao patótipo 001 de H. vastatrix, também foi observado que os genes são dominantes, pois a planta $F_{1} \mathrm{H} 511-1$ e as 87 plantas do $\mathrm{RC}_{\mathrm{R}}$ não apresentaram sinais do patógeno $\left(\chi^{2}=0,000 ; \mathrm{P}=1\right.$; Tabela 2). As 246 plantas da população $F_{2}$, quando receberam a inoculação, resultaram em 231 resistentes $(93,9 \%)$ e 15 suscetíveis (6,1\%). Esses resultados também evidenciam duas possíveis segregações fenotípicas significativas: 15:1 e 61:3. Para o padrão de segregação de 15:1, foi obtido um valor de qui-quadrado muito baixo $\left(\chi^{2}=0,009\right)$, ou seja, existe uma pequena diferença entre os dados observados e os esperados para esta segregação, o que indica melhor ajuste e uma probabilidade bem superior à obtida para a razão de 61:3 $\left(\chi^{2}=1,094\right)$.

Para verificar a consistência desses resultados, 115 plantas do $\mathrm{RC}_{\mathrm{S}}$ receberam inoculação do patótipo 001 de $H$. vastatrix. Nessa população, a hipótese de segregação de $3: 1\left(\chi^{2}=0,072 ; \mathrm{P}=0,787\right)$, esperada para reação de resistência condicionada por dois genes, não foi rejeitada, enquanto que a proporção de $7: 1$, esperada para três genes, sim. Estes resultados confirmam que a segregação 15:1 é a mais adequada. Com base nesses dados, dois genes dominantes e independentes controlam a reação de resistência do Híbrido de Timor UFV 443-03 ao patótipo 001 de $H$. vastatrix.

Em outros estudos de herança, que envolveram diferentes acessos de Híbrido de Timor, foram encontrados genótipos com um ou três genes de resistência. Em estudo com as raças II e XXV de H. vastatrix, observou-se herança monogênica dominante no Híbrido de Timor UFV 427-15. Também foram observados três genes dominantes governando a resistência às mesmas raças em outros seis Híbridos de Timor avaliados (Pereira, 1995). A explicação para os diferentes padrões de herança encontrados está na origem dos diferentes acessos do Híbrido de Timor. Esse germoplasma consiste em uma população heterogênea de plantas coletadas pelo CIFC na década 50, na Ilha de Timor. Essas plantas e as derivadas dos seus cruzamentos com cultivares de C. arabica foram introduzidas em vários centros experimentais do cafeeiro, inclusive no Brasil (Bettencourt, 1973).

Tabela 2. Segregação de resistência (R) e suscetibilidade (S) ao isolado monopustular do patótipo 001 de Hemileia vastatrix nas populações de cafeeiros analisadas.

\begin{tabular}{|c|c|c|c|c|c|c|c|c|}
\hline \multirow[t]{2}{*}{ Populações $^{(1)}$} & \multicolumn{2}{|c|}{ Número de plantas } & \multicolumn{2}{|c|}{ Proporção observada } & \multicolumn{2}{|c|}{ Proporção esperada } & \multirow[t]{2}{*}{$\chi^{2}$} & \multirow[t]{2}{*}{ Probabilidade } \\
\hline & $\mathrm{R}$ & $\mathrm{S}$ & $\mathrm{R}$ & $\mathrm{S}$ & $\mathrm{R}$ & $\mathrm{S}$ & & \\
\hline UFV 443-03 & 1 & 0 & 1 & 0 & 1 & 0 & - & - \\
\hline UFV 443-03 ® & 50 & 0 & 1 & 0 & 1 & 0 & 0,000 & 1,000 \\
\hline IAC 64 & 0 & 1 & 0 & 1 & 0 & 1 & - & - \\
\hline $\mathrm{F}_{1} \mathrm{H} 511-1$ & 1 & 0 & 1 & 0 & 1 & 0 & - & - \\
\hline $\mathrm{RC}_{\mathrm{R}}$ & 87 & 0 & 1 & 0 & 1 & 0 & 0,000 & 1,000 \\
\hline $\mathrm{F}_{2}(\mathrm{H} 511-1)$ & 231 & 15 & 15,4 & 1 & $15^{(2)}$ & 1 & 0,009 & 0,921 \\
\hline $\mathrm{RC}_{\mathrm{S}}$ & 85 & 30 & 2,8 & 1 & $3^{(2)}$ & 1 & 0,072 & 0,787 \\
\hline $\mathrm{F}_{2}(\mathrm{H}$ 511-1) & 231 & 15 & 46,2 & 3 & $61^{(3)}$ & 3 & 1,094 & 0,295 \\
\hline $\mathrm{RC}_{\mathrm{S}}$ & 85 & 30 & 2,8 & 1 & $7^{(3)}$ & 1 & 19,410 & 0,000 \\
\hline
\end{tabular}

${ }^{(1)} \otimes$, autofecundação controlada; $\mathrm{RC}_{\mathrm{R}}$, retrocruzamento resistente; $\mathrm{RC}_{\mathrm{S}}$, retrocruzamento suscetível. ${ }^{(2)}$ Hipótese de segregação para dois genes: $15: 1$ na geração $F_{2}$ e 3:1 no $\mathrm{RC}_{\mathrm{s}} \cdot{ }^{(3)}$ Hipótese de segregação de três genes: 61:3 na geração $\mathrm{F}_{2}$ e 7:1 no $\mathrm{RC}_{\mathrm{s}}$. 
Brito (2007) observou segregação monogênica dominante para a resistência do Híbrido de Timor UFV 427-15 à raça II de $H$. vastatrix e obteve marcadores moleculares AFLP ("amplified fragment length polymorphism") ligados ao gene de resistência nesse acesso de Híbrido de Timor. O primeiro trabalho de mapeamento de genes de resistência em Coffea spp. a $H$. vastatrix também foi realizado com marcadores AFLP (Prakash et al., 2004). Esses autores, ao analisarem uma população $\mathrm{F}_{2}$ derivada de C. liberica, identificaram 21 marcas AFLP ligadas ao gene de resistência $\mathrm{S}_{\mathrm{H}} 3$. Em trabalho posterior, Mahé et al. (2008) desenvolveram outros marcadores muito proximamente ligados ao gene $\mathrm{S}_{\mathrm{H}} 3$ de resistência à ferrugem do cafeeiro.

Os resultados obtidos no presente trabalho esclarecem a base genética da fonte de resistência do Híbrido de Timor UFV 443-03 à raça II e ao isolado P001 de $H$. vastatrix. Essas informações serão utilizadas em trabalhos moleculares, para identificação de marcadores proximamente ligados aos genes caracterizados, que poderão ser úteis na piramidação de genes de resistência do Híbrido de Timor em cultivares comerciais, visando à disponibilização de cultivares com resistência durável à ferrugem do cafeeiro.

\section{Conclusão}

Dois genes dominantes e independentes governam a reação de resistência do Híbrido de Timor UFV 443-03 à raça II e ao isolado P001 de Hemileia vastatrix.

\section{Agradecimentos}

Ao Conselho Nacional de Desenvolvimento Científico e Tecnológico, pela concessão da bolsa; à Fundação de Amparo à Pesquisa do Estado de Minas Gerais e ao Consórcio Brasileiro de Pesquisa e Desenvolvimento do Café, pelo apoio financeiro.

\section{Referências}

ALVARADO, G.A. Evolution of Hemileia vastatrix virulence in Colombia. In: ZAMBOLIM, L.; ZAMBOLIM, E.M.; VARZEA, V.M.P. (Ed.). Durable resistance to coffee leaf rust. Viçosa: UFV, 2005. p.99-115.

BETTENCOURT, A.J. Considerações gerais sobre o 'Híbrido de Timor'. Campinas: Instituto Agronômico, 1973. 20p. (Circular, 23).
BETTENCOURT, A.J.; NORONHA-WAGNER, M. Genetic factors conditioning resistance of Coffea arabica L. to Hemileia vastatrix Berk. \& Br. Agronomia Lusitana, v.31, p.285-292, 1971.

BETTENCOURT, A.J.; RODRIGUES JÚNIOR, C.J. Principles and practice of coffee breeding for resistance to rust and other diseases. In: CLARKE, R.J.; MACRAE, R. (Ed.). Coffee. London: Elsevier Applied Science, 1988. p.199-234.

BRITO, G.G. de. Mapeamento genético de marcadores AFLP ligados ao gene de resistência do cafeeiro à Hemileia vastatrix Berk. \& Br. 2007. 66p. Tese (Doutorado) - Universidade Federal de Viçosa, Viçosa.

CARDOSO, R.M.L. Novas raças de Hemileia vastatrix Berk. Et Br. no Brasil, métodos de identificação, e deteç̧ão de grupos fisiológicos em cafeeiros derivados do Híbrido de Timor. 1986. 102p. Dissertação (Mestrado) - Universidade Federal de Viçosa, Viçosa.

CASTILLO, Z.J. Breeding for rust resistance in Colombia. In: KUSHALAPPA, A.C.; ESKES, A.B. (Ed.). Coffee rust: epidemiology, resistance and management. Boca Raton: CRC Press, 1989. p.307-316.

CRUZ, C.D. Programa GENES: estatística experimental e matrizes. Viçosa: Imprensa Universitária, 2006. 285p.

ELYASI-GOMARI, S.; PANTELEEV, V.K. Virulence polymorphism of Puccinia recondita f. sp. tritici and effectiveness of $\mathrm{Lr}$ genes for leaf rust resistance of wheat in Ukraine. Plant Disease, v.90, p.853-857, 2006.

ESKES, A.B. The use of leaf disk inoculations in assessing resistance to coffee leaf rust (Hemileia vastatrix). Netherlands Journal of Plant Pathology, v.88, p.127-141, 1982.

KOLMER, J.A.; LONG, D.L.; HUGHES, M.E. Physiologic specialization of Puccinia triticina on wheat in the United States in 2005. Plant Disease, v.91, p.979-984, 2007.

KOLMER, J.A.; LONG, D.L.; HUGHES, M.E. Physiologic specialization of Puccinia triticina on wheat in the United States in 2006. Plant Disease, v.92, p.1241-1246, 2008.

LEONARD, K.J.; ANIKSTER, Y.; MANISTERSKI, J. Virulence associations in oat crown rust. Phytopathology, v.95, p.53-61, 2005.

MAHÉ, L.; COMBES, M.C.; VÁRZEA, V.M.P.; GUILHAUMON, C.; LASHERMES, P. Development of sequence characterized DNA markers linked to leaf rust (Hemileia vastatrix) resistance in coffee (Coffea arabica L.). Molecular Breeding, v.21, p.105-113, 2008.

MINISTÉRIO DA AGRICULTURA, PECUÁRIA E ABASTECIMENTO. Registro nacional de cultivares. Brasília: MAPA, 2008. Disponível em: <http://www.agricultura.gov.br/>. Acesso em: 16 jul. 2008.

NORONHA-WAGNER, M.; BETTENCOURT, A.J. Genetic study of resistance of Coffea spp. to leaf rust. I. Identification and behaviour of four factors conditioning disease reaction in Coffea arabica to twelve physiologic races of Hemileia vastatrix. Canadian Journal of Botany, v.45, p.2021-2031, 1967.

PEREIRA, A.A. Herança da resistência a Hemileia vastatrix Berk. Et Br. em cafeeiros derivados do Híbrido de Timor. 
1995. 66p. Tese (Doutorado) - Universidade Federal de Viçosa, Viçosa.

PRAKASH, N.S.; MARQUES, D.V.; VÁRZEA, V.M.P.; SILVA, M.C.; COMBES, M.C.; LASHERMES, P. Introgression molecular analysis of a leaf rust resistance gene from Coffea liberica into C. arabica L. Theoretical and Applied Genetics, v.109, p.13111317, 2004.

RODRIGUES JÚNIOR, C.J.; GONÇALVES, M.M.; VÁRZEA, V.M.P. Importância do Híbrido de Timor para o território e para o melhoramento da cafeicultura mundial. Revista de Ciências Agrárias, v.27, p.203-213, 2004.

TAMAYO, P.J.; VALE, F.X.R. do; ZAMBOLIM, L.; CHAVES, G.M.; PEREIRA, A.A. Resistência do Catimor à ferrugem e virulência de raças fisiológicas de Hemileia vastatrix Berk. \& Br. Fitopatologia Brasileira, v.20, p.572-576, 1995.
VÁRZEA, V.M.P.; MARQUES, D.V. Population variability of Hemileia vastatrix vs. coffee durable resistance. In: ZAMBOLIM, L.; ZAMBOLIM, E.M.; VÁRZEA, V.M.P. (Ed.). Durable resistance to coffee leaf rust. Viçosa: UFV, 2005. p.53-74.

WALLER, J.M.; BIGGER, M.; HILLOCKS, R.J. Coffee pests, diseases and their management. Oxfordshire: $\mathrm{CAB}$ International, 2007. 400p.

ZAMBOLIM, L.; CHAVES, G.M. Efeito de baixas temperaturas e do binômio temperatura-umidade relativa sobre a viabilidade dos uredosporos de Hemileia vastatrix Berk. et Br. e Uromyces phaseolityca Arth. Experientiae, v.17, p.151-184, 1974.

ZAMBOLIM, L.; VALE, F.X.R.D.; PEREIRA, A.A.; CHAVES, G.M. Manejo integrado das doenças do cafeeiro. In: ZAMBOLIM, L. (Ed.). Produção de café com qualidade. Viçosa: UFV, 1999. p.134-215.

Recebido em 2 de novembro de 2008 e aprovado em 27 de fevereiro de 2009 